\title{
Achieving Human Development in Nigeria through Philosophical Instruments
}

\author{
Charles C. Nweke \& Chukwugozie D. Nwoye \\ http://dx.doi./org/10.4314/ujah.v18i2.14
}

\begin{abstract}
The concept of human development conveys the thought of progressive unfolding of the entirety of the human person. It has as its end the attainment of the total well-being of an individual. However, often times, the end of human development appears truncated due to some existential circumstances surrounding the individual. Arguably, with the perceived Nigerian existential circumstances of maladministration that has led to extreme poverty, poor infrastructure, fallen standard of education, negative political proclivity in terms of ethnic chauvinism and religious bigotry, serve as albatross to authentic human development. The intent of this paper, therefore, is to argue the fact that through some core philosophical instruments, an individual in Nigeria can still attain total genuine well-being, human development.
\end{abstract}

Keywords: Development, Nigeria, Instrument, Philosophy

\section{Introduction}

In this piece, the researchers are out to argue the case that the issue of human development in Nigeria is a mirage. This is as a result of numerous factors that are supposed to be the indicators of society that is developed human wise not being in place in Nigeria. The paper however, makes the argument that with some philosophical instruments, namely: self-evaluativeness, universalism and objectivity, Nigeria can get it right human development wise. To execute this task, the paper is thus formatted: I looks into the 
concept of development; II reviews the idea of philosophy; III delves into Nigeria and the state of human development in it; IV presents discussion on philosophy as a way out; $\mathrm{V}$ is the summary and conclusion.

\section{Development}

Development is a noun which means "the act of developing or the process of being developed" and the verb, develop, means, "to make or become more mature, more advanced, more complete, more organized, more detailed, etc."(Mairi P. 366) From the study of the origin and meaning of words, development is from the French verb, 'veloper', meaning to wrap, essentially, to make to grow slowly, fuller, larger, stronger and better. It connotes progression, growth and maturity given as an end process actualizable by a being (Njoku O.C.7). Panoramically, development can be viewed as a gradual but progressive growth of something, from tender stage to more advanced, stronger, refined, etc., stage. As regards human society, development is variegated.

At the individual plane, it implies increased skill and capability to earn more income, greater freedom of action, creativity, selfdiscipline, responsibility and general material and psychological well-being. Essentially, the feat of these is meaningful only in relation to the state of society. At the societal plane, development signifies increased capacity to regulate internal and external relations, increase in capability to guard national independence, self-sufficiency in food production, high level of employment, equal distribution of social services, self-reliance, equitable economic opportunities, skill to find solutions to internal problems, education, infrastructure, etc. Therefore, development purports to improve, to make progress, change for the better, higher income or 
better living standard, increase in the quantity of goods and services within the reach of the people which leads to the improvement of the quality of their well-being. It gives the idea of social and material progress that empowers the people to have more control over their environment. In mind of the modern day pluralistic society, Dag Hammarskjold advocated a development that should be inside-driven. For him, development should be particular-environment driven within multiple and diverse one world, that is, that societies have languages to form their own normative standard and goals which do not need necessarily to dovetail with those of the west (qtd. in Soola 2). For Henry Odera Oruka, his conceptualization of development is such that, "If $\mathrm{N}$ is a nation, the concept ' $\mathrm{N}$ is developed' means that in $\mathrm{N}$ the people have their economic and socio-cultural needs fully satisfied, i.e. that in $\mathrm{N}$ one has all the social freedoms such as economic, political, cultural, intellectual, religious and sexual freedoms."(qtd. in Kuçuradi Joanna 128).

For Mihailo Markovic, two meanings underlie development. One is growth from the uncomplicated to the more complex one as a result of external situations. This meaning hinges on continuity. It smacks of Leibniz's statement of all organic development as "augmentation and diminution of already formed animals." It reminisces of Schelling's discovery in all organic nature a successive development of the one and the same organization principle of climbing up. It recalls Darwin's articulation that new species emanate from aggregation of countless small variations. On the second meaning which is the opposite meaning of development, it lays stress on discontinuity, transformation given rise to by internal determinants. Markovic buttresses this second meaning by citing Heraclitus in his position that the moving force 
of all becoming is an inner conflict of rival forces. And finally, that the notion of a qualitative development has been offered the most articulate elucidation in Hegel.

Each form has inevitably, an essential inner limitation, a characteristic which is part of its identity but is incompatible with all other characteristic. Once this limitation is overcome (aufgehoven), the form turns into something new in which all the positive elements of the previous form are preserved within a more progressive form. Hegel called the principle regulating all such qualitative, structural change the negation of the negation. (qtd. in Kuçuradi Joanna 69 )

For D.P. Chattopdhyaya, the concept of development is almost always said of people, country, nation, society and the economy of a state. For him, minimally, three differing connotations of development are easily seen, (a) additive (quantitative), (b) additive (qualitative), and (c) adjustive (both qualitative and quantitative). Instantiating the quantitative perspective, he says, the increase of population, increase in the size of an ethnic group may be seen as a sign of its development. Though not necessarily so. Economically, he says, developed countries show a static, and sometimes even negative, birth-rate. Two, that it is often debated that the qualitative enrichment of life positively warrant birthcontrol, beside other requirements such as freedom from poverty, freedom from diseases, recreative facilities and creative opportunities, etc. Third, that adjustive development is at the same time qualitative and quantitative. That people or groups of juxtaposable cultural or moral digits experience less conflict in most of their mutual relationships. He further opines that 
sometimes, juxtaposable gifts of the related groups are inclined to advancing conflict and co-operation. In the domain of economic and technological advancement, this maladjustive feature is obviously noticed. Maladjustive, he maintains, create tension and sometimes result in competition and even conflict. The preceding notwithstanding, he avers that competition and conflict need not be seen all the time in negative light. In most instances, competition and conflict advance efforts resulting in excellence. In peaceful conditions, adjustment and re-adjustment, characterized by competition and conflict, establish and maintain a kind of dynamic balance. This is seen more in places of industry and trade and less so in the areas of literature and fine arts, science and technology. (qtd. in Kuçuradi Joanna 37-38 ) Looking at development in today's society, Evandro Agazzi says,

In fact when we speak of development in the current socioeconomical and political sense nowadays, we refer to a progress which concerns large human communities, which can and must be promoted by human initiative, which must lead to an improvement of human life conditions, i.e. to a real progress of mankind, or at least of these portions of mankind for which the said development is envisaged. (qtd. in Kuçuradi Joanna 22)

The above are different definitions of development. At this juncture, it is imperative that we consider the ramifications of development of which human development is one of them.

\section{Facets of Development}

Economic Development: For Henry Odera Oruka, a state is said to be economically developed if it meets its economic needs. That is, if the people living in that state have economic freedom or 
liberty. Essentially, it means that there is economic freedom in that state which purports that people in that state are not exploited, and that they have the ability and opportunity to meet their economic needs (qtd. in Kuçuradi Joanna 128).

Socio-Economic Development: This is the process of social and economic growth in a society gauged with indicators such as GDP, life expectancy, illiteracy and ratios of employment. Changes in less tangible factors are equally deliberated upon, viz; personal dignity, freedom of association, personal safety and freedom from fear of physical hurt and the level of participation in civil society. Agents of socio-economic development could be seen as a result of new technologies, changes in law, changes in the physical environment and ecological changes, etc (Hawkins H. and Valatin R. 27). In brief, this form of development entails a full social and economic emancipation of individuals and the society.

Political Development: Totally, political development hinges on the development of the constitutions, attitudes and values that shape the political power/system of a society (Political Development). According to H. O. Oruka, "Similarly, a nation is politically developed only if there is political freedom in such a nation and here political freedom entails the fulfillment of such political rights as the right of expression, the right of assembly, the right to vote and to hold different political opinions and to aspire to be a leader etc." (qtd. in Kuçuradi Joanna 128)

Moral Development: For Kohlberg in his The Concept of Moral Development, children form methods of thinking through their experiences which has comprehension of moral concepts like justice, rights, equality and welfare of human beings. Actualization 
of moral maturity takes six stages of moral reasoning grouped into three main planes. Particular level shows a basic shift in the social moral perspective of the individual. Stage one is heteronymous orientation paying particular attention on preventing breaking of rules and regulation that are enforced by punishment. This is characterized by geocentricism and inability to consider the views of other instrumental, pragmatic value of an action. It is a game of reciprocity. At the second stage, what is right is what is fair in an equal exchange. Protection of each person's interest is the benchmark in any bargain.

Persons in the third stage define what is right in terms of the stereotypic roles that define being good, for example, good brother, mother, sister etc. My being good means keeping mutual relationships such as trust, respect, gratitude, etc., in the perspective of the local community or family. Stage four makes a shift from defining what is right in terms of local norms and role expectation to what is right as expected by the larger society. Stage five is a theoretical end point which follows from ethical reasoning but the final state of moral development entails an empirical reasoning rooted in the ethical fairness principles from which moral laws would be viewed.

Cultural development: For Jishi S, this is seen as the refinement and renewed arbitrary cultures and the adoption of a civilized and modern culture putting into cognizance the power of discarding those ugly aspects of the culture of the society which are harmful to social development. It includes building a culture that would bring about revival in the lives of the members of the society. Cultural development entails co-opting culture into all 
developmental policies, whether related to education, environment or tourism. Also, it means development of the cultural sector through creative industries. For Joanna Kuçuradi, cultural development is seen in two perspectives: western and third world, respectively. The western idea of cultural development "... was the broadening, for the masses, of the possibility to have 'access and participation to culture', that is to the activities considered to afford to individuals the possibility to develop their potentialities as human beings -e.g. to artistic, scientific, philosophical activities." (Kuçuradi Joanna 12) In the Third World countries which do not participate in the so-called western or European culture, Kuçuradi says, people comprehend from cultural development, the advancement of their "cultural identity."

In decolonized Third World countries, he says, it was seen as developing- that is, identifying and reconstructing- their own culture, which, they presuppose, was hamstrung or forgotten under the towering influence of western culture in the course of colonization period. They began making effort to identify the culture, that is, the notion of man and the conception pertaining to what is considered valuable, which they consider is, and desire to be, their own. The preceding idea is what Kuçuradi considered is ongoing in Africa at the moment. He further says, in Third World countries, which are "in the process of modernization", and which have opted for 'modernization", cultural development is comprehended as 'resurrection' or 'revival' of the culture, that is to say, of the notions of man and of what is worthwhile, prevailing among them before they encountered the West. (Kuçuradi Joanna 12) 
Scientific and Technological Development: This implies that work done to ensure the development of skill, knowledge and expertise which in practice are being applied in the field of science. It means the development of science and technology for promotion of industrial production contributing towards the national economic development plans. It includes increased extraction and utilization of domestic raw material and the promotion of industrial production enterprises based on modern science and technology. Summarily, one can say that scientific and technological development means the application of scientific knowledge for technological innovation. It means operating practical and result oriented programmes and training geared towards transformation of the nation's economy from consumer-type to manufacture-type in the background of sound knowledge.

Leaning on the idea of freedom, Henry Odera Oruka argues that, a nation is culturally developed, intellectually developed, religiously developed and sexually developed on the sole condition that there is cultural freedom, intellectual freedom, and religious freedom, in addition to anti-religious freedom and sexual freedom (that is, not in the sense of promiscuity but freedom to love and marry a person of one's own taste and choice) in that nation. (qtd. in Kuçuradi Joanna 128)

On the part of human development, a school of thought sees it as human capacity to expand in his own consciousness and therefore his power over the self. For Evandro Agazzi,

..., the concept of development, applied to human beings, reveals a moral connotation much more than a material one, both in the sense that moral reasons must be those which 
push the promotion of this development, and in the sense that the promotion of human dignity must remain its most fundamental goal, even in those cases in which it may be more 'urgent' to subvene to more elementary material needs. (qtd. in Kuçuradi Joanna 31)

Linking human development with national development, Evandro Agazzi further maintained that, a genuine development of a human person will be in his or her possibility to display all his or her potentialities at the most different stages of self-realization. In the same vein, advancing the development of a country will ultimately mean assisting the people to attain the ultimate possible realization of material, spiritual, social, political well-being, which may dovetail well into the specificity of its historical heritage, of its traditions, customs, beliefs, and values. ( qtd. in Kuçuradi Joanna 30)

Human Development Report Office (HDRO) portrays human development as seen below. Human development emerged as a result of global discourses on the connections between economic growth and development in the course of the second half of the 20th Century. In the early 1960s there were intense agitations to "dethrone" GDP: economic growth had evolved as both a leading objective, and indicator, of national development in many countries even though GDP was never hoped on to be used as a benchmark of well-being. During 1970s and 80s progress discussions deliberated on making use of alternative measures to move beyond GDP. That included placing greater importance on employment, accompanied by redistribution with growth, and also whether people had their necessary needs met. 
The above notions are aided in creating the route for the human development approach, which has its import as widening the richness of human life, instead of just the richness of the economy in which human beings live. It is an approach that is targeted at enabling fair opportunities and choices for everybody. The question one may ask is this, how do these notions add together into the human development approach?

People: the human development approach has its attention as bettering the lives people lead instead of presuming that economic development will turn, magically, into more opportunities for everybody. Income increase is an essential instrument to development, instead of an end in itself.

Opportunities: human development is geared towards handing down to individuals, greater freedom and opportunities to live lives they value. In essence, it implies honing individuals' abilities and enabling them the opportunity to utilize them. Take for instance, giving a girl education would enhance her skills, but it is of less importance if she is denied access to jobs, or does not have the required skills for the local labour market. "Three foundations for human development are to live a healthy and creative life, to be knowledgeable, and to have access to resources needed for a decent standard of living. Many other aspects are important too, especially in helping to create the right conditions for human development, such as environmental sustainability or equality between men and women." (HDRO Outreach)

Choices: basically human development is powered towards greater choice. Its intent is to furnish individuals with opportunities, but not persisting that they make use of them. Nobody can vouchsafe 
human happiness, and the choices people make are their own responsibility. Build up to development - human development ought to at least enable an atmosphere for people, individually and collectively, to grow to their full potential and to access a reasonable opportunity of leading fruitful and innovative lives that they aspire for.

On another note, the human development approach, that is the brain child of the economist Mahbub Ul Haq, is premised on Amartya Sen's work on human capabilities, couched on whether people are able to "be" and "do" those things they value in their live. These include: "Beings: well fed, sheltered, healthy. Doings: work, education, voting, participating in community life. Freedom of choice is central: someone choosing to be hungry (during a religious fast say) is quite different to someone who is hungry because they cannot afford to buy food." (HDRO Outreach)

For Sabina Alkire, "Human development is a process of enlarging people's choices. The most critical ones are to lead a long and healthy life, to be educated and to enjoy a decent standard of living. Additional choices include political freedom, guaranteed human rights and self-respect - what Adam Smith called the ability to mix with others without being "ashamed to appear in public." (2) Again, human development is seen as,

...creating an environment in which people can develop their full potential and lead productive, creative lives in accord with their needs and interests. People are the real wealth of nations. Development is thus about expanding the choices people have to lead lives that they value. And it is thus about much more than economic growth, which is only 
a means - if a very important one - of enlarging people's choices. Fundamental to enlarging these choices is building human capabilities - the range of things that people can do or be in life. (Sabina Alkire 6)

For Sabina Alkire as well, the illustration of human development as expanding people's choices, however basic, is not sufficient. It must be augmented by procedural principles like equity, efficiency, sustainability, respect for human rights and responsibility. This is because human freedoms could well be extended in manners that worsen inequality, that are wasteful, or short-sighted, or that breaches the human rights of one group in order to enlarge the freedoms of another group. In addition, the groups of interest differ widely, and add women cum racial or ethnic groups, certain age brackets, or geographical groups. (24)

Human development makes obvious the objectives that numerous economists, political leaders, citizens and activists have recognized in variant manners across time. The objectives are:

Well-being: A focus on expanding people's real freedoms, enabling people to flourish. [Opportunity freedom] Agency: Supporting people and groups as actors; helping them to help themselves.[Process freedom] Justice: Seeking to expand wellbeing and agency in ways that expand equity, sustain outcomes across time, respect human rights, limit environmental destruction and respect other goals of a society. [Plural Principles] ....So Human Development aims to expand people's freedoms - the worthwhile capabilities they value -and to empower people to engage actively in development processes. And it seeks to do so in 
ways that appropriately advance equity, efficiency, sustainability and other key principles. (Sabina Alkire 24)

\section{Philosophy}

In the class of scholars, it is no longer news that the concept philosophy defies a univocally accepted definition. "An embarrassment for professional philosophers is that they cannot produce any succinct, or even agreed, definition of their profession. 'What is philosophy?' is itself a philosophical question." (Lacey A. R.253) That is, by implication, philosophers have their different opinions about the concept yet saying what the concept stands for. In the opinion of Mbaegbu,

In spite of all the disagreements surrounding the meaning of philosophy, most philosophers would view it at least as a form of rational activity, indeed, thinking at its most rational level, generally, about reality and what it means for man. Philosophy is a critical inquiry, for instance, on the nature of the universe and man in particular. One pursuing this type of inquiry is usually said to be a seeker of wisdom (Mbaegbu C.C. 6)

However, the only commonly agreed definition of philosophy is from its etymological view, "14th Century: from Greek philosophia love of wisdom, from philo- loving + sophia wisdom."(Mairi R.1040) It is important to note that philosophizing is natural with human beings. It is that common to every human being whether Igbo, Yoruba or Hausa. The ability to do philosophy is intrinsic with every human being and to all cultural entities since the foundational cause of it all is curiosity or "wonder" as most great minds in philosophy would call it. It is in tandem with this 
reality that Aristotle correctly remarks that human beings by nature desire to know. Accentuating the very fact of inherent nature of philosophy to man, Hyland submits thus: "Philosophy is the culmination, the highest consequence of what it is to be human.'(Hyland Drew A. 26-27) Despite this common commonality of philosophy to every person, it is imperative to make it lucidly clear that philosophy is of first order activity and second order activity. By first order activity otherwise known as informal, ordinary or unprofessional philosophy is understood to mean the general beliefs of a certain group of people --take for instance, the Igbo, Yoruba or Hausa people-- about man, physical objects and reality in general. It is a "we", collective beliefs of a group of people in relation to their unique environment. However, second order activity understanding of philosophy equally known as formal, official, academic or professional philosophizing is a later development in man and the society too. Mbaegbu mirrors this understanding better when he opines:

That the ability to philosophize is natural to man is not the same as saying that man has always philosophized in the academic meaning of the word, in the sense of a coherent, systematic inquiry (the true meaning of philosophy) since power and its use are different things altogether. Philosophy in this sense as opposed to its loose meaning of common beliefs of a people about reality, man, etc., is man's later development, a time in society when human thought has attained a certain level and there are favourable social conditions which make man's philosophic ability come to fruition (Mbaegbu C.C. 7)

Implicatively, philosophy in its academic sense came about, "when almost all the necessities of life and the things that make for 
comfort and recreation had been secured.'(Mbaegbu C.C. 7) Therefore, philosophy in this second order activity is purported to mean the conscious critical individual reflection on human experiences, on physical objects, intangible beings, on man, etc., and how he understands and interprets the reality around him or her. "It is a critical, systematic, thinking, generally thought at its deepest level." (Mbaegbu C.C. 8) Therefore, what makes an individual a philosopher, a lover of wisdom, in the sense under study, "Is not the mere fact of thinking about materials important to philosophy, such as man, culture, religion, art but thinking or reflecting on them logically, systematically, coherently, with reason as the sole guide."(Mbaegbu C.C. 9) It is a personal and, above all, knowing thoughtful critical exercise. It is a reflexively, self-evaluating, critical exercise consciously done on an individual, personal ground. It is this understanding that informs the definition of philosophy by John Dewey to run thus: "criticism of criticisms."(Mbaegbu C.C. 12) It is philosophy understood at this level that we are concerned with here.

\section{Human Development: How Has It Fared in Nigeria?}

"Nigeria, one-third larger than Texas and the most populous country in Africa, is situated on the Gulf of Guinea in West Africa. Its neighbors are Benin, Niger, Cameroon, and Chad. The lower course of the Niger River flows south through the western part of the country into the Gulf of Guinea. Swamps and mangrove forests border the southern coast; inland are hardwood forests."(Info please) According to Emejulu, the amalgamation of Northern and Southern Protectorates by Sir Frederick Lugard in 1914 saw the creation of the most populous country in Africa, Nigeria. It is inhabited by about 250 ethnic groups and is made up of large kingdoms with distinct customs, traditions and languages. Among 
the larger and politically dominant ethnic groups are Igbo, Hausa and Yoruba. Other ethnic groups include: Edo, Effik, Ibibio, Tiv, Nupe, Kaanuri, Ijaw, Igala, Jukun, etc. Rivers such as Niger, Benue, Cross River, Yobe, etc., and their tributaries play significant function in bringing the people together; and River Niger has been a tremendous communication artery or connection among these different peoples (Emejulu I 311-312) It has about 173.6 million people in terms of population with English language as the official language.

The hallmark of human development is the provision of total wellbeing of the individuals in a country. But the question is, is Nigeria in anyway close to approximating the ideals of human development? In Nigeria, does an average Nigerian has the opportunity of making his or her choice in terms of what to eat, clothing and shelter? As a matter of fact, it may be surprising to some that, most Nigerians cannot boast of a well balanced meal either in the morning, afternoon or night, not to talk of having three square meals in a day. This is buttressed by the now cliché that an average Nigerian lives below one dollars in a day. What of housing? How many Nigerians live in a house worthy of the name? Behind the façade of few mansions that litter the streets of some developed states (cities) in Nigeria, are found uncountable shanties and ghettos where most Nigerians live day in day out. What of health care system? Many Nigerians die daily due to inaccessibility of hospitals in the country. The ones that exist are either not operating on optimal level or they are simply an apology. And that is why the few wealthy Nigerians who can afford the bill travel overseas for better treatments and those who cannot afford it die haplessly. As such, life expectancy in Nigeria is very short and mortality very much in the increase. In a situation like this can 
somebody talk of having a choice much less making a choice? What of clothing? Most Nigerians make use of used articles of clothing known as Okirika or worse still, they go for the Chinese ones that look new but of poor quality. Not that they do not see the superior quality ones that are brand new, they recourse to Okirika or inferior Chinese materials for want of choice, lack of the wherewithal. What of the educational system in Nigeria that is supposed to grant people better life due to the advantages attached to it? In Nigeria today, there is no gainsaying the fact that the standard of education is an apology. Apart from the few private schools and some missionary schools and those who recourse to overseas education, public schools, that is, government sponsored schools in Nigeria -- tertiary institutions not exempted-- are nothing to write home about. The schools are quite dilapidated. The ones not dilapidated are best described as white painted sepulcher.

No adequate equipments and teaching aids to facilitate quality learning. At the end of the day, the products are people who are unfit to proceed to higher institutions and those graduating from higher institutions are grossly unemployable. With this scenario, one sees a low standard of living starring an average Nigerian in the face; a life where making of choice is grossly lacking.

What of political freedom? The instance of political assignations in the country abound. Nigerian political landscape is filled with realities of thuggery, violence ranging from ballot box snatching to maiming and outright killing of innocent voters. The recent elections conducted in Nigeria testify to these. Nigerians are not allowed to politically voice their opinions in the act of governance. This is instantiated by the fact of election rigging. Peoples' choices 
in elections are falsely and forcefully replaced with candidates other than their choice. And the electorates are helpless in such situations.

Related to political freedom is the issue of human rights in Nigeria. It is a common knowledge that the inalienable rights of most Nigerians are not guaranteed. Ranging from unlawful detention of Nigerians in police and prison custodies to outright extra judicial killings attest to this fact. The current detention of Nnamdi Kanu in prison custody at the behest of the presidency even when he has been granted bail by a competent judicial court with legitimate order bears eloquent testimony to the issue in question. Similar to this is the killing of innocent farmers by Fulani herdsmen without the appropriate quarters doing the needful because of one interest or the other. And these puts these Nigerian victims of this ugly development in the position to question their self-respect, and to ask, are we still part of this country called Nigeria?

The bottom line of the above discourse is that the issue of human development in Nigeria leaves much to be desired. And the question is, who or what is responsible? Indubitably, and primarily too, the blame is on the doorsteps of Nigerian government. Why and how can Nigeria get out of this seeming aporia?

\section{Philosophical Instruments and Human Development in Nigeria}

Nigerian government is majorly to be blamed because they have proven irresponsive and irresponsible towards discharging their duties. It is enshrined in Nigerian constitution that the primary responsibility of the president is to protect lives and properties of every Nigerian. Whether this is done today is left for one to fathom. Also, it is their responsibility to provide education, health 
care, electricity, pipe born water, good road networks, etc. Instead, they have used the money for common good for their own selfish interests and that of their cronies. The question becomes, have we Nigerians actually, in a critical manner, self-evaluatively ask ourselves why the situation is the case? If we have employed this instrument of philosophy, we could have understood that the problem lies with government and ourselves too, because we have refused to take the government to task for not living up to their responsibility. The result of this self-evaluation in earnest could have caused Nigerians to do the needful either by going through civil disobedience in order for government to hearken to our needs or other forms of demonstrations that will bring them to their knees. It is after they must have been forced to listen and care for the needs of Nigerians that they will learn to imbibe the philosophical tool of universalism.

Universalism purports the idea of looking at interests through the lens of all involved and not from a particular interest. It is due to the proclivity towards particular interests that human development in Nigeria is grossly lacking behind. Those in leadership position in Nigeria, first and foremost, look at the state of origin before they either address the need of the people in the said area or tap into their natural resources or talents. In that way, they have been short changing the common good of all Nigerians. With universalism as an instrument imbibed by our leaders, the issue of human development will be greatly addressed in the country. That is to say, problems will be addressed not minding the state of origin of the people involved. Ethnic group origins will not be used as yardstick but the interests of all Nigerians as the yardstick. Associated with universalism is the instrument of objectivity. Objectivity implies seeing truth from the stand point of view points 
and not from points of view, that is, seeing truth wherever it is found irrespective of the state of origin. It means that one's opinion is not foreclosed or disregarded in advance because of one's ethnic background. And also that no particular ethnic group will see their particular truth values as supreme or the benchmark for measuring other ethnic groups' truth values. It means that truth must be arrived at in matters of national discussions through better arguments in the background fair dialogical process. That is to say, that no particular ethnic group will see their truth contents as the best without going through the sluice of public discussion where the arguments will be weighed in terms of their strengths and weaknesses before acceptance or rejection, especially in matters affecting the nation as whole. It means openness to other person's point of view in mind of arriving at an unparticular truth for the interest of all. It is in this way that objectivity of truth is arrived at. In this manner, even development will be guaranteed through objective and not subjective policy-making -which has been the norm-- thereby facilitating quicker human development in the country.

With these instruments imbibed in earnestness, no doubt, Nigeria will be expunged from the list of countries with low human development index.

\section{Summary and Conclusion}

In this discourse, we started by explicating the key words that formed the kernel of this paper such as development, human development, philosophy and Nigeria as it geared towards making lucid the object of discussion. Thereafter, it showed that the issue of human development in Nigeria gives no well meaning Nigeria any cause to jubilate. The paper went on lay the blame of lack of 
human development in Nigeria on the doorsteps of the leaders, primarily, and the led as well. As a way forward, it suggested the particular instruments of philosophy such as self-evaluativeness that is couched in critical thinking, universalism and objectivity as sure fire to lift Nigeria out of the seeming aporia of grossly low human development.

Charles C. Nweke

\& Chukwugozie D. Nwoye

Nnamdi Azikiwe University, Awka

nkesun2002@yahoo.com

tencencdon@yahoo.com

\section{Works Cited}

Burnge M. Towards a philosophy of Technology, Boston: Allyn and Bacon Inc, 1974

Hawkins H. and Valatin R. Development and the Information Age. Ohawa, aidre and UNSTD, 1997.

HDRO Outreach 20th April, 2016

http://hdr.undp.org/en/content/what-human-development.

Hyland Drew A. The Origins of Philosophy, Its Rise in Myth and

The Pre-Socratics. New York: Capricorn Books G.P.

Putnam's Sons, 1973), pp. 26-27.

Ifeyinwa Emejulu, "Nigerian Peoples: Ethnic and Language Groupings" Readings in African Thought and Culture Vol.1. Edited by Aghamelu and Asomugha. Aguata: Strong Tower Books, 2009. 
Jishi S. $2^{\text {nd }}$ February 2012 "What it means to be civilized"

@ww.Helium.com/items/11069209/homhtm retrieved 2/02/2012.

Kohlberg Lawrence.26" March 2012 "The Concept of Moral Development" www.selhelp.magazine.comarticles.moraldev.

Kuçuradi Joanna (ed) "The Idea of Development Between its Past and its Future" in International Federation of Philosophical Societies Vol.1 Ankara 1993, pp.9-128.

Lacey A. R. A Dictionary of Philosophy 3rd ed. London: Taylor \& Francis e-Library, 2005

Mbaegbu C.C. Problems of African Philosophy. Unpublished Lecture notes for Master's Students of Nnamdi Azikiwe University, Awka 2007

Mairi R. Chambers 2Ist Century Dictionary of Current English London: London University Press. 1998.

Njoku O.C. "Corruption: The Bane of Nigeria's Development" Eugene C. Anowai (ed) Corruption: The Bane of Nigeria's Development.. Awka: Demercury Bright Printing \& Publishing Co., 2011.

"PoliticalDevelopment" 6 th of March, 2012.

http:/www.political.development.com/text/index.htm.

Sabina Alkire. 2010 "Human Development: Definitions, Critiques, and Related Concepts" OPHI working paper no. 36 www.ophi.org.uk pp.1-54.

Soola E.O. Communicating for Developmental Purposes. Ibadan: Kraft Books, 2003.

www.infoplease.com/country/nigeria.html 